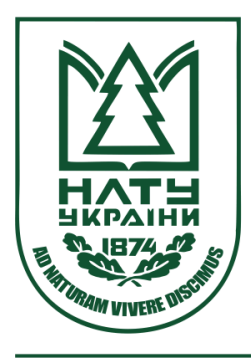

Науковий вісник НлтУ України Scientific Bulletin of UNFU

https://nv.nltu.edu.ua

https://doi.org/10.15421/40280816

$@ \bowtie$ Correspondence author

Article received 05.10.2018 p.

Article accepted $25.10 .2018 \mathrm{p}$.

V. M. Lovynska

удк 630*2:633.877.3(292.486)

Дніпровський держсавний аграрно-економічний університет, м. Дніпро, Украйна

\title{
НАДЗЕМНА ФІТОМАСА СТОВБУРІВ PINUS SYLVESTRIS L. У ДЕРЕВОСТАНАХ ПІВНІЧНОГО СТЕПУ УКРАЇНИ
}

\begin{abstract}
Нормативно-довідникові дані є основним інформаційним базисом під час оцінювання біологічної продуктивності лісотвірних порід, зокрема сосни звичайної, у насадженнях різних лісорослинних зон України. Наведено результати моделювання надземної фітомаси компонентів стовбура дерев сосни звичайної у штучних деревостанах Північного Степу України. Математичному моделюванню підлягали такі компоненти надземної фітомаси стовбурів дерев сосни звичайної, як: об'єм деревини стовбура, об'єм кори стовбура та об'єм стовбура в корі. Представлено результати кореляційного аналізу та основні статистики об'ємів деревини, кори та стовбура в корі з основними таксаційними показниками досліджуваної породи - віком, висотою та діаметром на висоті 1,3 м дерева. Розроблено дво- і трифакторні регресійні алометричні моделі, які показують залежність об'єму компонентів надземної фітомаси дерев сосни звичайної від зазначених таксаційних характеристик. на підстаі отриманих моделей побудовано нормативно-довідникові таблиці для оцінювання компонентів надземної фітомаси стовбура дерев сосни звичайної у свіжозрубаному та абсолютно сухому станах. Показано, що надземна фітомаса деревини та стовбура в корі сосни звичайної збільшується із висотою та діаметром дерева. Водночас фітомаса компонента кори стовбура має тенденцію до зниження із висотою за сталої величини діаметра стовбура.
\end{abstract}

Ключові слова: сосна звичайна; компоненти стовбура; модель; діаметр; висота.

Вступ. Біопродуктивність лісів є головною характеристикою, яка визначає напрям процесів у лісових екосистемах, тому іiї використовують з метою здійснення екологічного моніторингу та під час сталого ведення лісового господарства. Оцінка фітомаси деревних складових лісових екосистем $є$ важливою складовою під час моделювання продуктивності лісів та встановлення їх вуглецедепонувальної ємності (Utkin, 1975; Usolcev, 1988; Monserud et al., 1996). На сьогодні в Україні за цим питанням проведено чимало грунтовних досліджень професор П.І. Лакида, учні його наукової школи, які отримали результати 3 фітомаси, вуглецедепонувальних можливостей, киснепродуктивності для основних лісотвірних порід лісів різних природно-кліматичних зон нашої країни (Lakyda \& Blishhik, 2010; Lakyda et al., 2011; Lakyda, 2012; Lakyda \& Mateiko, 2016). Однак питання щодо визначення зазначених показників в умовах Степу, а саме Північної його частини, залишається поки що відкритим. 3 огляду на це, вивчення надземної фітомаси сосни звичайної, що $є$ головною хвойною породою зазначеного регіону, виконує переважно рекреаційно-оздоровчу функцію (Lovinska \& Sytnyk, 2016), є вкрай актуальним.

Мета дослідження - розроблення комплексу нормативно-інформаційного забезпечення з фітомаси компонентів стовбура сосни звичайної в умовах Північного Степу України.

Матеріали й методи дослідження. Оцінювання компонентів фітомаси стовбура сосни звичайної охоплювало виконання польових лісотаксаційних робіт на тимчасових пробних площах (ТПП) та лабораторних науково-дослідних робіт з метою встановлення якісних характеристик стовбура модельних дерев (МД). Під час досліджень використано методики проф. П. І. Лакиди (Lakyda, 2002).

Як експериментальний матеріал було використано дані 21 ТПП, які репрезентують штучні деревостани сосни звичайної в межах Дніпропетровського регіону та підпорядковані Державному агентству лісових ресурсів. Закладку ТПП проводили з урахуванням лісівничо-таксаційних вимог, що регламентують здійснення лісовпорядних робіт ("Площі пробні лісовпорядні. Метод закладання" (SOU 02.02-37-476, 2006). Пофракційну оцінку компонентів фітомаси стовбуру проводили для $63 \mathrm{MД,} \mathrm{діапазон} \mathrm{віку} \mathrm{яких} \mathrm{становив} \mathrm{від} 9$ до 90 років. Для відібраних МД визначали висоту та діаметр стовбура (Shvidenko et al., 1987).

Встановлення якісних характеристик компонентів фітомаси стовбура (природна та базисна щільність) проводили з використанням програм ZRIZ та PLOT, які розробив П. І. Лакида (Lakyda, 2002).

Статистичну обробку даних та математичне моделювання здійснювали з використанням програм Excel та STATISTICA 12.0. Основним критерієм для оцінки адекватності одержаних моделей були значення коефіцієнтів детермінації $\left(\mathrm{R}^{2}\right)$. Моделюванню підлягали такі

Інформація про авторів:

Ловинська Вікторія Миколаївна, канд. біол. наук, доцент, кафедра садово-паркового господарства. Email: glub@ukr.net; https://orcid.org/0000-0002-7359-9443

Цитування за ДСтУ: Ловинська В. М. Надземна фітомаса стовбурів Pinus Sylvestris L. у деревостанах північного степу України. Науковий вісник НЛтУ України. 2018, т. 28, № 8. С. 79-82.

Citation APA: Lovynska, V. M. (2018). Aboveground phytomass of the trunk of Pinus Sylvestris L. stands within northern steppe of Ukraine. Scientific Bulletin of UNFU, 28(8), 79-82. https://doi.org/10.15421/40280816 
компоненти надземної фітомаси стовбурів дерев сосни звичайної, як: об'єм деревини стовбура (Vдер); об'єм кори стовбура (Vк); об'єм стовбура в корі (Vст).

Результати дослідження та їх обговорення. Розроблення системи нормативів для оцінки надземної фітомаси дерев сосни звичайної за допомогою моделювання $є$ основою під час складання нормативно-довідникових таблиць фітомаси соснових деревостанів у статистиці, що дасть змогу вирішити економічні та екологічні проблеми досліджуваного регіону.

На першому етапі досліджень проведено статистичний аналіз робочого масиву даних, результати якого представлено в табл. 1.

Табл. 1. Основні статистики розподілу таксаційних показників та компонентів фітомаси об'сму стовбурів сосни звичайної

\begin{tabular}{|c|c|c|c|c|c|c|}
\hline \multirow{2}{*}{ Ознака } & \multicolumn{2}{|c|}{ Значення } & \multicolumn{4}{|c|}{ Статистики } \\
\cline { 2 - 7 } & $\min$ & $\max$ & $X$ & $\Sigma$ & $A$ & $E$ \\
\hline$a$, років & 9 & 90 & 53 & 23,2 & $-0,513$ & $-0,673$ \\
\hline$d_{1,3}, \mathrm{~cm}$ & 4,0 & 41,7 & 20,6 & 7,7 & 0,189 & 0,747 \\
\hline$h, \mathrm{M}$ & 4,2 & 30,0 & 18,9 & 6,3 & $-1,101$ & 0,650 \\
\hline$(V \partial e p), \mathrm{m}^{3}$ & 0,002 & 1,601 & 0,328 & 0,296 & 2,252 & 6,903 \\
\hline$(V \kappa), \mathrm{m}^{3}$ & 0,001 & 0,266 & 0,055 & 0,049 & 2,199 & 6,673 \\
\hline$(V c m), \mathrm{m}^{3}$ & 0,003 & 1,748 & 0,383 & 0,337 & 2,183 & 6,314 \\
\hline
\end{tabular}

Як видно $з$ наведених даних, розподіл таксаційних параметрів загалом відповідає нормальному, з огляду на нижчі значення асиметрії та ексцесу від критичних (Yantsev, 2012). Від'ємні значення асиметрії мають вік та висоту дерева, що свідчать про зсув кривої розподілу ліворуч. Про плосковершинність кривої розподілу свідчить від'ємний ексцес для віку дерева. Перевищення допустимих критичних значень асиметрії та ексцесу відзначено для всіх варіантів розподілу об'ємів компонентів фітомаси стовбурів сосни звичайної.

Процес моделювання фітомаси стовбурів прямо залежить від його складових, у цьому випадку таксаційних показників. Тому наступним кроком було проведення кореляційного аналізу між пошуковими параметрами із встановленням їх тісноти зв'язків на 5-відсотковому рівні значущості (табл. 2).

Табл. 2. Коефіцієнти кореляції об'єму компонентів фітомаси стовбурів $з$ основними таксаційними показниками дерев сосни звичайної

\begin{tabular}{|c|c|c|c|}
\hline $\begin{array}{c}\text { Такса- } \\
\text { ційні по- } \\
\text { казники } \\
\text { дерев }\end{array}$ & \multicolumn{3}{|c|}{ Об'єм компонентів фітомаси стовбура } \\
\cline { 2 - 4 } & $\begin{array}{c}\text { деревина стов- }(V \partial e p), \mathrm{M}^{3} \\
\text { буроки стовбура } \\
(V \kappa), \mathrm{M}^{3}\end{array}$ & $\begin{array}{c}\text { стовбур у корі } \\
(V c m), \mathrm{M}^{3}\end{array}$ \\
\hline$d_{1,3}, \mathrm{~cm}$ & 0,52 & 0,56 & 0,53 \\
\hline$h, \mathrm{~m}$ & 0,90 & 0,81 & 0,91 \\
\hline
\end{tabular}

Отримані дані вказують на сильний прямий кореляційний зв'язок об'єму компонентів фітомаси стовбурів дерев сосни звичайної із діаметром на висоті грудей $\left(d_{1,3}\right)$, тоді як таких параметрів, як вік $(a)$ та висота $(h)$ дерева, зафіксовано середньої сили зв'язок із об'ємами досліджуваних компонентів стовбура.

Моделювання компонентів надземної фітомаси стовбурів сосни звичайної здійснювали 3 використанням масиву даних, де як головні аргументи рівнянь використовували вік, діаметр дерева на висоті грудей та його висоту. Розроблені дво- і трифакторні математичні моделі об'єму деревини, кори стовбура та стовбура в корі дерев сосни звичайної наведено у табл. 3. Отримані моделі мають високі коефіцієнти детермінації $\left(Q^{2}=0,87-0,96\right)$, що особливо характерно для моделей розрахунку об'єму деревини та об'єму деревини в корі стовбуру. Двофакторні моделі із введенням у рівняння діаметра на висоті грудей та висоти стовбура $є$ більш практичними, внаслідок чого їх і було використано для розрахунку об'ємів компонентів фітомаси стовбура.

Табл. 3. Моделі для оцінювання фітомаси компонентів стовбура дерев сосни звичайної

\begin{tabular}{|c|c|c|}
\hline $\begin{array}{c}\text { № мо- } \\
\text { делі }\end{array}$ & Вид рівняння & $\begin{array}{c}\text { Коеф. де- } \\
\text { термінації }\end{array}$ \\
\hline \multicolumn{3}{|c|}{ Об'єм деревини стовбурів дерев } \\
\hline 1 & $V д е р=0,000026 \cdot d^{1,988} \cdot h^{1,205} \cdot a^{-0,099}$ & 0,96 \\
\hline 2 & $V д е р=0,00002 \cdot d^{1,967} \cdot h^{1,175}$ & 0,96 \\
\hline \multicolumn{3}{|c|}{ Об'єм кори стовбура } \\
\hline 3 & $V \kappa о р и=0,000028 \cdot d^{2,326} \cdot h^{-0,355} \cdot a^{0,348}$ & 0,87 \\
\hline 4 & $V \kappa o p u=0,000064 \cdot d^{2,398} \cdot h^{-0,232}$ & 0,87 \\
\hline \multicolumn{3}{|c|}{ Об'єм стовбурів у корі дерев } \\
\hline 5 & $V c m$ у корi $=0,000042 \cdot d^{2,039} \cdot h^{0,936} \cdot a^{-0,020}$ & 0,96 \\
\hline 6 & $V c m$ корi $=0,000040 \cdot d^{2,035} \cdot h^{0,930}$ & 0,96 \\
\hline
\end{tabular}

Як видно із представлених залежностей, показники ступеня діаметра $\left(d_{1,3}\right)$ та висоти дерева у варіантах визначення об'ємів деревини та стовбура в корі мають додатні значення. Це свідчить про збільшення об'єму компонентів стовбура сосни звичайної під час зростання зазначених таксаційних показників. Показник ступеня висоти дерева в моделях для визначення об'єму кори стовбура відрізняється від'ємним значенням, що свідчить про зменшення пошукової величини зі збільшенням висоти. Трифакторні моделі для розрахунку об'єму деревини та деревини в корі містять такий чинник впливу, як вік, ступінь якого має від'ємні значення, а це визначає зниження показників об'єму із віком дерева.

На основі представлених у табл. 3 моделей $(2,4,6)$, у яких як чинники впливу виступають висота і діаметр стовбура $\left(d_{1,3}\right)$, які легко вимірюються в натурі та 3 використанням якісних показників стовбура проведено розробку нормативно-інформаційного забезпечення оцінки компонентів фітомаси стовбурів дерев у їх свіжозрубаному та абсолютно сухому стані. Показники щільності компонентів стовбура сосни звичайної мають такі значення: середня природна щільність деревини $831 \kappa \Gamma^{\cdot}\left(\mathrm{м}^{3}\right)^{-1}$; середня природна щільність кори 661 кг $\left(\mathrm{M}^{3}\right)^{-1}$; середня природна щільність деревини в корі - $801 \kappa^{\cdot} \cdot\left(\mathrm{м}^{3}\right)^{-1}$; середня базисна щільність деревини - 414 кг. $\left(\mathrm{M}^{3}\right)^{-1}$; середня базисна щільність кори 317 кг $\left(\mathrm{м}^{3}\right)^{-1}$; середня базисна щільність деревини в коpi -398 кг $\left(\mathrm{M}^{3}\right)^{-1}$ (Sytnyk et al., 2016; Lovynska \& Lakyda, 2017).

Фрагменти нормативно-довідникових даних для оцінювання фітомаси стовбурів, розрахованих для дерев сосни діаметром від 4 до $40 \mathrm{~cm}$ та висотою від 4 до 30 м, наведено у табл. 4-7.

Табл. 4. Фітомаса деревини стовбурів дерев сосни звичайної в абсолютно сухому стані, кг

\begin{tabular}{|c|c|c|c|c|c|c|c|c|c|c|}
\hline \multirow{2}{*}{ 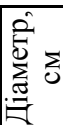 } & \multicolumn{10}{|c|}{ Висота, м } \\
\hline & 4 & 6 & 8 & 10 & 12 & 14 & 16 & 18 & 20 & 22 \\
\hline 4 & 0,6 & 1,0 & 1,5 & 1,9 & & & & & & \\
\hline 6 & 1,4 & 2,3 & 3,2 & 4,2 & 5,2 & & & & & \\
\hline 8 & & 4,1 & 5,7 & 7,4 & 9,2 & 11,0 & & & & \\
\hline 10 & & & 8,8 & 11,5 & 14,2 & 17,1 & & & & \\
\hline 12 & & & 12,6 & 16,4 & 20,4 & 24,4 & \begin{tabular}{|l}
28,6 \\
\end{tabular} & & & \\
\hline 14 & & & & 22,3 & 27,6 & 33,0 & \begin{tabular}{|l}
38,7 \\
\end{tabular} & 44,4 & & \\
\hline 16 & & & & 28,9 & 35,9 & 43,0 & 50,3 & 57,7 & 65,3 & \\
\hline 18 & & & & & 45,2 & 54,2 & 63,4 & 72,8 & 82,4 & \\
\hline 20 & & & & & 55,6 & 66,7 & 78,0 & \begin{tabular}{|l|l}
89,6 \\
\end{tabular} & 101,4 & 113, \\
\hline 22 & & & & & & 80,4 & \begin{tabular}{|l|}
94,1 \\
\end{tabular} & 108,0 & 122,3 & 136,7 \\
\hline 24 & & & & & & 95,4 & 111,6 & 128,2 & 145,1 & 162,3 \\
\hline
\end{tabular}


Табл. 5. Фітомаса кори стовбурів дерев сосни звичайної в абсолютно сухому стані, кг

\begin{tabular}{|c|c|c|c|c|c|c|c|c|c|c|}
\hline Діаметр, & \multicolumn{10}{|c|}{ см } \\
\cline { 2 - 12 } & 4 & 6 & 8 & 10 & 12 & 14 & 16 & 18 & 20 & 22 \\
\hline 4 & 0,4 & 0,4 & 0,3 & 1,0 & & & & & & \\
\hline 6 & 1,1 & 1,0 & 0,9 & 0,9 & 0,8 & & & & & \\
\hline 8 & & 2,0 & 1,8 & 1,7 & 1,7 & 1,6 & & & & \\
\hline 10 & & & 3,1 & 3,0 & 2,9 & 2,8 & & & & \\
\hline 12 & & & 4,8 & 4,6 & 4,4 & 4,3 & 4,1 & & & \\
\hline 14 & & & & 6,7 & 6,4 & 6,2 & 6,0 & 5,8 & & \\
\hline 16 & & & & 9,2 & 8,8 & 8,5 & 8,2 & 8,0 & 7,8 & \\
\hline 18 & & & & & 11,7 & 11,3 & 10,9 & 10,6 & 10,4 & \\
\hline 20 & & & & & 15,0 & 14,5 & 14,1 & 13,7 & 13,3 & 13,1 \\
\hline 22 & & & & & & 18,2 & 17,7 & 17,2 & 16,8 & 16,4 \\
\hline 24 & & & & & & 22,4 & 21,8 & 21,2 & 20,7 & 20,2 \\
\hline
\end{tabular}

Табл. 6. Фітомаса стовбурів у корі дерев сосни звичайної у свіжозрубаному стані, кг

\begin{tabular}{|c|c|c|c|c|c|c|c|c|c|c|}
\hline \multirow{2}{*}{ 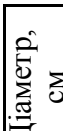 } & \multicolumn{10}{|c|}{ Висота, м } \\
\hline & 4 & 6 & 8 & 10 & 12 & 14 & 16 & 18 & 20 & 22 \\
\hline 4 & 2,1 & 2,9 & 3,6 & 4,5 & & & & & & \\
\hline 6 & 5,1 & 6,7 & 8,4 & 10,3 & 12,2 & & & & & \\
\hline 8 & & 12,2 & 15,3 & 18,5 & 21,9 & 25,4 & & & & \\
\hline 10 & & & 24,3 & 29,2 & 34,5 & 40,0 & & & & \\
\hline 12 & & & 35,5 & 42,6 & 50,1 & 57,9 & 65,9 & & & \\
\hline 14 & & & & 58,6 & \begin{tabular}{|l|}
68,7 \\
\end{tabular} & \begin{tabular}{|l|l|}
79,2 \\
\end{tabular} & 90,1 & 101,2 & & \\
\hline 16 & & & & 77,2 & \begin{tabular}{|l|}
90,3 \\
\end{tabular} & 104,0 & 118,1 & 132,6 & 147,5 & \\
\hline 18 & & & & & 115,1 & 132,2 & 150,0 & 168,3 & 187,0 & \\
\hline 20 & & & & & 143,0 & 164,0 & 185,8 & 208,3 & 231,3 & 254,8 \\
\hline 22 & & & & & & 199,4 & 225,6 & 252,7 & 280,4 & 308,7 \\
\hline 24 & & & & & & 238,3 & 269,4 & 301,5 & 334,3 & 367,9 \\
\hline
\end{tabular}

Табл. 7. Фітомаса стовбурів у корі дерев сосни звичайної в абсолютно сухому стані, кг

\begin{tabular}{|c|c|c|c|c|c|c|c|c|c|c|}
\hline \multirow{2}{*}{ 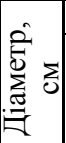 } & \multicolumn{10}{|c|}{ Висота, м } \\
\hline & 4 & 6 & 8 & 10 & 12 & 14 & 16 & 18 & 20 & 22 \\
\hline 4 & 1,0 & 1,4 & 1,8 & 2,9 & & & & & & \\
\hline 6 & 2,5 & 3,3 & 4,2 & 5,1 & 6,0 & & & & & \\
\hline 8 & & 6,0 & 7,5 & 9,1 & 10,8 & 12,6 & & & & \\
\hline 10 & & & 12,0 & 14,5 & 17,1 & 19,8 & & & & \\
\hline 12 & & & 17,5 & 21,0 & 24,8 & 28,7 & 32,7 & & & \\
\hline 14 & & & & 28,9 & 34,0 & 39,2 & 44,6 & 50,2 & & \\
\hline 16 & & & & 38,1 & 44,7 & 51,5 & 58,5 & 65,7 & 73,2 & \\
\hline 18 & & & & & 56,9 & 65,4 & 74,3 & 83,4 & 92,8 & \\
\hline 20 & & & & & \begin{tabular}{|l}
70,6 \\
\end{tabular} & 81,2 & 92,0 & 103,2 & 114,7 & 126 \\
\hline 22 & & & & & & 98,6 & 111,7 & 125,2 & 139,0 & 153 \\
\hline 24 & & & & & & 117,9 & 133,4 & 149,4 & 165,7 & 182 \\
\hline
\end{tabular}

За наведеними даними видно, що зі збільшенням висоти та діаметра на висоті 1,3 м спостерігаємо зростання компонентів фітомаси деревини та стовбурів у корі, тоді як для компонента кори в межах одного ступеня товщини дерева зі збільшенням висоти дерева зменшується його фітомаса.
Цей факт можна пояснити тим, що в умовах степової зони, де гідрологічний режим не $\epsilon$ оптимальним для росту рослин, а також за досить високих температурних умов, зі зростанням віку рослин, а відповідно, їх висоти, для дерев характерним є збільшення збіжистості стовбура, із відповідним формуванням товстішої кори на менших висотах.

Висновки. Отримані нормативно-довідникові таблиці оцінки компонентів надземної фітомаси стовбурів можна використовувати під час встановлення екологічного та економічного їх потенціалу, а також оцінювання вуглецедепонувальних властивостей для соснових насаджень на регіональному рівні. Розроблені нормативи для сосни звичайної будуть сприяти комплексному використанню лісових ресурсів в умовах Північного Степу України.

\section{Перелік використаних джерел}

Lakyda, P. I. (2002). Phytomass of forests of Ukraine. Ternopil: Zbruch, 256 p. [In Ukrainian].

Lakyda, P. I. (2012). Artificial pine forest stands of Polissya of Ukraine - forecast of growth and productivity. Korsun-Shevchenkivskyi: FOP Maidachenko I. S., 171 p. [In Ukrainian].

Lakyda, P. I., \& Mateiko, I. M. (2016). Phytomass and carbon deposide of ash trees and stands of Rightside Foreststeppe of Ukraine. Kyiv: Komprynt, 156 p. [In Ukrainian].

Lakyda, P. I., Vasylyshyn, R. D., Lashchenko, A. H., \& Terentiev, A. Yu. (2011). Normative assessment of aboveground phytomass components of trees of main forestforming species of Ukraine. Kyiv: Vyd. dim "Ekoinform", 192 p. [In Ukrainian].

Lakyda, P. I., \& Blishhik, I. V. (2010). Phytomass alders of Western Polissya of Ukraine. Korsun-Shevchenkivskij: FOP Majdachenko I. S., 237 p. [In Ukrainian].

Lovynska, V. M., \& Lakyda, P. I. (2017). Wood and bark density of trunks of Scots pine in the Northern Steppe of Ukraine. Forestry and Forest Melioration, 130, 185-192. [In Ukrainian].

Monserud, R. A., Onuchin, A. A., \& Tchebakova, N. M. (1996). Needle, crown, stem, and root phytomass of Pinus sylvestris stands in Russia. Forest Ecology and Management, 82, 59-67. https://doi.org/10.1016/0378-1127(95)03689-X

Shvidenko, A. Z., Strochinskii, A. A., \& Poliakov, V. K. (1987). Normative reference material for forest inventory of Ukraine and Moldova. Kyiv: Urozay, 560 p. [In Ukrainian].

Sytnyk, S. A., Lovynska, V. M., \& Maslikova, K. P. (2016). The basic debsity stems of the main wood species in the forest stands within Northern Steppe of Ukraine. Ecology and noospherology, 27(3-4), 27-34. https://doi.org/10.15421/031611

Usolcev, V. A. (1988). Growth and structure of stands phytomass. Novosibirsk: Publishing "Nauka", 253 p. [In Russian].

Utkin, A. I. (1975). Biologicheskaia produktivnost lesov (metody izucheniia i rezultaty). [Bioproductivity of forests (methods of study and results)]. Lesovedenie i lesovodstvo: Itogi nauki i tekhniki, 1, 9189. [In Russian].

Yantsev, A. V. (2012). Selection of statistical criteria. Symferopol: Izdatelstvo TNU, 136 p. [In Russian].

В. Н. Ловинская

Днепровский государственный аграрно-экономический университет, г. Днепр, Украина

\section{НАДЗЕМНАЯ ФИТОМАССА СТВОЛОВ PINUS SYLVESTRIS L.} В ДРЕВОСТОЯХ СЕВЕРНОЙ СТЕПИ УКРАИНЫ

Нормативно-справочные данные являются основным информационным базисом при оценке биологической продуктивности лесообразующих пород, в частности сосны обыкновенной, в насаждениях различных лесорастительных зон Украины. Приведены результаты моделирования надземной фитомассы компонентов ствола деревьев сосны обыкновенной в искусственных древостоях Северной Степи Украины. Математическому моделированию подлежали такие компоненты надземной фитомассы стволов деревьев сосны обыкновенной, как объем ствола, объем коры ствола и объем ствола в коре. Представлены результаты корреляционного анализа и основные статистики объемов древесины, коры и ствола в коре с основными таксационными показателями исследуемой породы - возрастом, высотой и диаметром на высоте 1,3 м дерева. Разработаны двух- и трехфакторные регрессионные аллометрические модели, которые показывают зависимость объема компонентов 
надземной фитомассы деревьев сосны обыкновенной от указанных таксационных характеристик. На основе полученных моделей построены нормативно-справочные таблицы для оценки компонентов надземной фитомассы ствола деревьев сосны обыкновенной в свежесрубленном и абсолютно сухом состояниях. Показано, что надземная фитомасса древесины и ствола в коре сосны обыкновенной увеличивается с высотой и диаметром дерева. В то же время фитомасса компонента коры ствола имеет тенденцию к снижению с увеличением высоты при постоянной величине диаметра ствола на высоте 1,3 м дерева.

Ключевые слова: сосна обыкновенная; компоненты ствола; модель; диаметр; высота.

V. M. Lovynska

Dnipro State Agrarian and Economic University, Dnipro, Ukraine

\section{ABOVEGROUND PHYTOMASS OF THE TRUNK OF PINUS SYLVESTRIS L. STANDS WITHIN NORTHERN} STEPPE OF UKRAINE

Reference database are the main information basis for the assessing of the forest forming species biological productivity, in particular, Scots pine, in the plantations of different forest zone of Ukraine. The purpose of our research was to develop a complex normative standard evaluation for trunk components of aboveground phytomass of Scots pine trees in the condition of the Northern Steppe of Ukraine. The method of evaluating of Scots pine trunk components included field forest taxation work on temporary sample plots and laboratory research work with the establishment of qualitative characteristics of the model trees trunk. The investigated pine stands of the artificial origin, of age ranging from 9 to 90 years, 21 sample plots were established. Pine stands phytomass was studied based on the results of measuring the height and diameter $(d b h)$ of the selected model trees. The following components of the aboveground phytomass of pine trees trunks are used for mathematical modeling - the volume of the trunk timber, the volume of the trunk bark and the volume of the trunk in the bark. The results of the correlation analysis and the main statistics of the volume of the trunk timber, the volume of the trunk bark and the volume of the trunk in the bark with the basic biometric parameters of the investigated species as age, height and diameter at the $1.3 \mathrm{~m}$ height of tree are presented. Two- and three-factor regression alometric models, which show the dependence of the volume of aboveground phytomass components of pine trees with biometric characteristics have been developed. On the basis of the obtained models, a normative table for the evaluation of the components of the aboveground phytomass of the pine trees trunk in freshly cut and absolutely dry conditions was constructed. It is shown, that aboveground phytomass of trunk timber and trunk in the bark increased with tree height and diameter. At the same time phytomass of bark component had tendency to decrease with the tree height with the constant value of trunk diameter. Developed alometric models for estimating the trunk components of the aboveground phytomass can be used for the detailed assessment of some ecological functions (carbon deposition) and energy potential in pine stands of the investigated region.

Keywords: Scots pine; trunk components; model; diameter; height. 